\title{
Reproductive performance of dairy farms in western Buenos Aires province, Argentina
}

\author{
Gonzalo Ferreira ${ }^{1,2}$ \\ CREA Lincoln, Red de Innovación y Desarrollo de la Zona Oeste (RIDZO), Asociación Argentina de Consorcios Regionales \\ de Experimentación Agrícola, Sarmiento 1236, (1041) Ciudad Autónoma de Buenos Aires, Argentina
}

\begin{abstract}
The objective of this study was to describe the reproductive performance of 23 grazing-based dairy farms from western Buenos Aires province in Argentina. The data set included data from the breeding season starting in May 2011 and ending in March 2012. Submission, conception, and pregnancy rates ranged from 42.4 to $70.2 \%, 20.1$ to $44.9 \%$, and 10.3 to $24.5 \%$, respectively. No correlation was observed between conception and submission rates, suggesting that dairy farms with poor submission rates but with relatively high conception rates might increase pregnancy rates by simply putting more effort into increasing estrus detection and submission rates. Decreases in submission and conception rates were observed among 21-d cycles, indicating seasonal variation. A greater number of cows in estrus at the beginning of the breeding period could have facilitated estrus detection and therefore increased submission rates. In addition, restarting the breeding activities with timed artificial insemination programs may explain the highest submission rates at the beginning of the breeding period. A first decrease of 5.1 percentage units in conception rate was observed during the spring (October-November) and an additional decrease of 2.4 percentage units in conception rate was observed during the summer (January-February). Decreases in conception rates could be related to high intakes of high-protein diets, heat stress, or a combination of both. Attenuating heat stress during the summer may be critical for maximizing conception rates in grazing systems from western Buenos Aires province.
\end{abstract}

Key words: reproductive performance, conception rate, grazing

\section{INTRODUCTION}

High milk yield and good reproductive performance are essential to ensure the profitability of dairy farms.

Received April 9, 2013.

Accepted August 19, 2013.

${ }^{1}$ Current address: Department of Dairy Science, Virginia Tech, 175 West Campus Drive, Blacksburg, VA 24060.

${ }^{2}$ Corresponding author: gonf@vt.edu
Pregnancy rate is an overall measure of reproductive performance (de Vries et al., 2010; Ferguson and Skidmore, 2013), and it is calculated as the number of cows that become pregnant divided by the number of cows eligible to become pregnant within a certain time period. Poor pregnancy rates can be attributed to poor estrus detection and submission (i.e., insemination) rates, a poor conception rate, or a combination of both (Ferguson and Skidmore, 2013).

Reproductive performance has declined while milk yield has increased in the last few decades. López et al. (2004) observed a shorter duration of estrus for high-producing cows than for low-producing cows (6.2 and $10.9 \mathrm{~h}$, respectively). Efficiency in the detection of estrus is crucial so that AI can be performed at an appropriate time relative to ovulation (Walsh et al., 2010). Data from Ferguson and Skidmore (2013) not only showed that conception rate at first service does not decrease with very high submission rates at first service $(P<0.75)$, but also showed that conception rates at first service $>35 \%$ can be obtained even with submission rates at first service $>74 \%$.

Benchmarking permits visualization of how dairy farmers are performing relative to their peers. In Argentina, the nonprofit organization Asociación Argentina de Consorcios Regionales de Experimentación Agrícola (AACREA; Buenos Aires, Argentina) stimulates benchmarking among producers so that they can see where they are regarding performance, set new goals, and improve their production practices. The objectives of this paper were (1) to describe the reproductive performance of dairy farms belonging to AACREA and located in western Buenos Aires (BA) province in Argentina; (2) to describe relationships between submission and conception rates; and (3) to show whether exist seasonal variations of reproductive performance exist on these farms.

\section{MATERIALS AND METHODS}

\section{Dairy Farming Systems}

Twenty-three dairy farms (farms A to W) belonging to AACREA within western BA province were included 
in this study. All herds were composed of Holstein cows, except one that had Jersey cows (farm D, Table 1). Herd size ranged from 180 to 1,900 cows. Cows from almost all farms $(\mathrm{n}=21)$ grazed pastures (e.g., ryegrass and alfalfa pastures) in intensive grazing systems supplemented with silages and concentrates. Cows from 2 farms were housed in open lots and had no access to pasture paddocks; on these farms, forages other than corn silage were provided as alfalfa or grass silages or green-chopped alfalfa.

Most farms provided shade in small pens or at the milking parlor to some or all lactating cows during the summer (Table 1). Shade typically consisted of black mesh shade or tree plantations. When present, ventilation or water sprinklers were only available in the waiting area of the milking parlor (Table 1).

Estrus detection was based on visual observation of estrus behavior $(\mathrm{n}=11)$, on disappearance of paint from the tail head of the cows $(\mathrm{n}=8)$, or on a combination of both $(\mathrm{n}=2$; Table 1$)$. Except for 2 farms that inseminated lactating cows with sex-sorted semen (farms $\mathrm{V}$ and $\mathrm{W}$ ), all farms inseminated lactating cows with conventional semen. No synchronization or timed AI (TAI) programs were used on a majority of the farms $(\mathrm{n}=11)$. Five farms used TAI programs alone and 3 farms used both synchronization and TAI programs (Table 1).

\section{Data Collection and Management}

Data from farms were retrieved using commercial reproductive management software (DairyComp 305, Valley Agricultural Software Inc., Tulare, CA; Syscord-Tamb, Lincoln, Argentina; Protambo Master 3.0, DIRSA SH, Gonnet, Argentina; SW Dr. Sola, SW Agropecuaria SRL, San Carlos, Argentina). On 20 farms, breeding was discontinued from mid-March to mid-May to avoid calving during the warm season (mid-December to mid-February); on 3 farms, breeding was practiced all year round. The experimental data

Table 1. Descriptive management of dairy farms from the western region of Buenos Aires province in Argentina

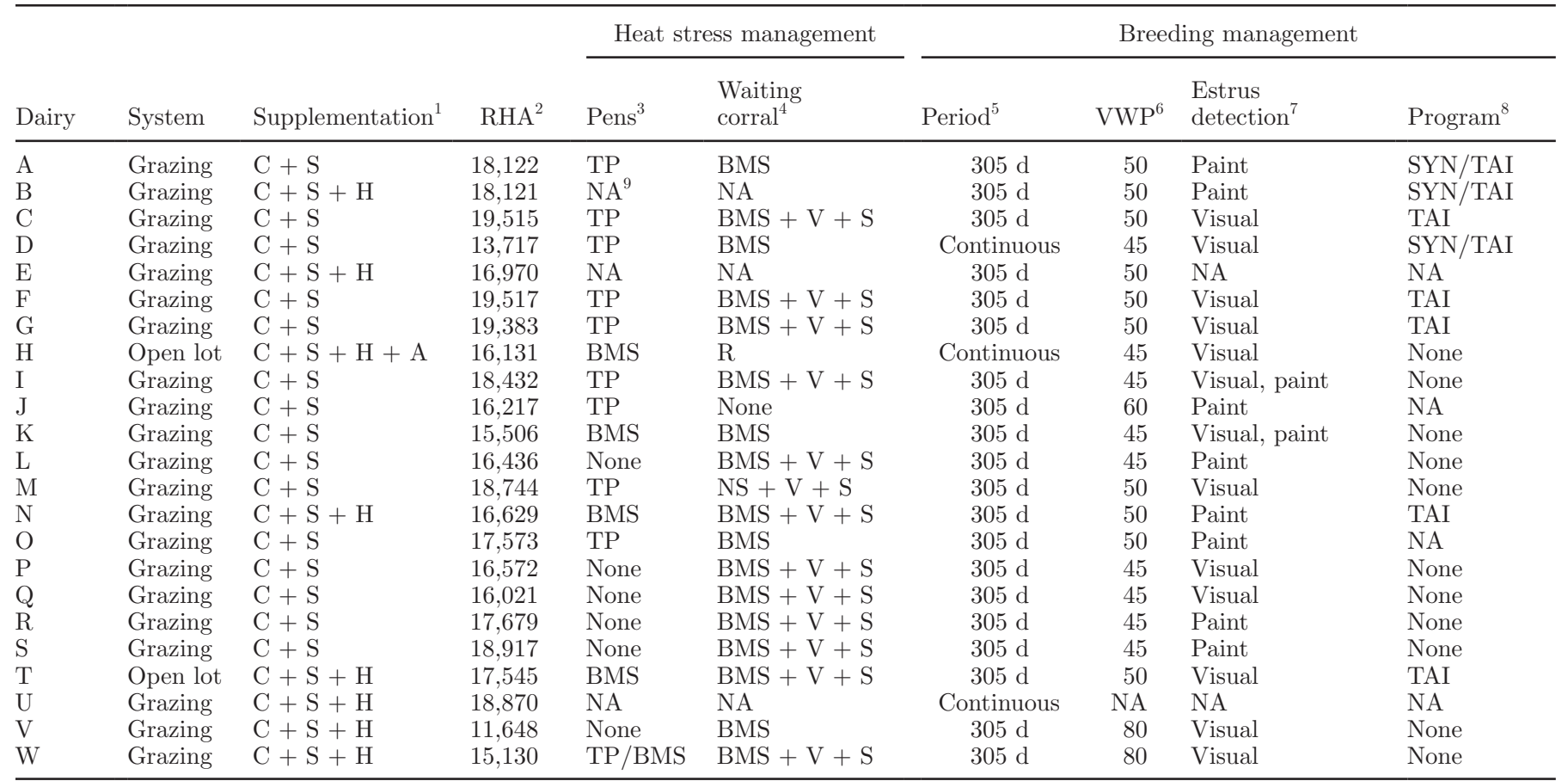

${ }^{1}$ Major supplements utilized: $\mathrm{C}=$ concentrate; $\mathrm{S}=$ silages (mainly corn, sorghum, and grass silages); $\mathrm{H}=$ hay; $\mathrm{A}=$ green-chopped alfalfa.

${ }^{2}$ Rolling herd average (lb/cow per year).

${ }^{3}$ Shading system while not in the milking parlor: BMS $=$ black mesh shade; $\mathrm{TP}=$ tree plantations.

${ }^{4}$ Heat stress abatement system at waiting area of the parlor: BMS = black mesh shade; $\mathrm{R}=$ roof; $\mathrm{V}=$ ventilators; $\mathrm{S}=$ water sprinklers; $\mathrm{NS}=$ natural shade.

${ }^{5}$ Continuous = all-year breedings; $305 \mathrm{~d}=$ breedings for only $305 \mathrm{~d}$ (starting typically around mid-May).

${ }^{6}$ Reported voluntary waiting period.

${ }^{7}$ Main method for estrus detection.

${ }^{8}$ Program $=$ implementation of synchronization $(\mathrm{SYN})$ or timed AI (TAI) protocols.

${ }^{9} \mathrm{NA}=$ not available. 
set included data from the breeding season starting in May 2011 and ending in March 2012. For this analysis, the overall or accumulated submission, conception, and pregnancy rates were normalized using data from the first fourteen 21-d cycles. For those farms that bred cows all year round, May 1 was used as the starting point of the breeding season. The data set included data from 57,940 cows eligible to become pregnant among fourteen 21-d reproductive cycles.

When using protocols that depend on detected estrus for $\mathrm{AI}$, the major limitation to maximizing pregnancy rates in lactating dairy cows is the AI submission rate (Cartmill et al., 2001). Even though all farms from this study inseminated after detected estrus, cows may have occasionally been subjected to synchronization or TAI programs (Table 1). Because in TAI programs, the AI submission rate is $100 \%$ (Cartmill et al., 2001), estrus detection and submission rates tend to be the same. In this database, submission rate is confounded with estrus detection rate. Therefore, for this study, submission rate was defined as the proportion of cows eligible to become pregnant that were AI in a $21-\mathrm{d}$ period.

\section{Statistical Analyses}

The relationship between submission and conception rates was analyzed by simple regression analysis using Minitab 15 (Minitab Inc., State College, PA). The effect of reproductive cycle (i.e., seasonal variation) on reproductive rates was evaluated as repeated measures using the MIXED procedure of SAS 9.3 (SAS Institute Inc., Cary, NC). The model included the effects of dairy farm (random, $\mathrm{df}=22$ ) and reproductive cycle (fixed, $\mathrm{df}=13$ ) and the residual error (random, $\mathrm{df}=284)$. The autoregressive heterogeneous covariance structure was selected for analysis with repeated measures based on the Akaike information criterion.

\section{RESULTS AND DISCUSSION}

Among all dairies, the overall submission, conception, and pregnancy rates ranged from 42.4 to $70.2 \%$, 20.1 to $44.9 \%$, and 10.3 to $24.5 \%$, respectively (Table 2 ). These ranges imply great variation in the reproductive performance of dairy herds of western BA, and therefore, great potential for improvements in the dairy industry of this region. A quantitative assessment of BCS was not available for this analysis, although diversity of nutritional management may explain the variable conception rates. Poor estrus detection rates, and hence poor submission rates, may be related to inappropriate facilities or even lack of motivation of personnel (Heersche and Nebel, 1994). For example, some dairy farms that rely on painting of the tail head to detect estrus may not have appropriate facilities (parlor gangways or head-locks) for adequate paint interpretation. In addition, heat detection under grazing management conditions may be a tedious and frustrating chore when personnel are exposed to harsh weather or poor environmental conditions (e.g., muddy roads and pens or low temperatures). Another reason for the poor conception rate observed on some of these dairy farms (farms $\mathrm{V}$ and $\mathrm{W}$, Table 2) may be related to the use of sex-sorted semen in lactating cows, which is known to result in lower conception rates (Hutchinson et al., 2013).

No correlation was observed between submission and conception rates $(P>0.10$; Figure 1$)$. Two dairy farms used sex-sorted semen to breed lactating cows and had poor conception rates (farms $\mathrm{V}$ and $\mathrm{W}$, with conception rates of 26.2 and $22.9 \%$, respectively; Table 2 ). Artificial insemination with sex-sorted semen has resulted in low conception rates, which may be related to reduced sperm quality and viability (Hutchinson et al., 2013). When these 2 farms were excluded from the data set, a lack of correlation between submission and conception rates was still observed $(P>0.10)$. A lack of correlation between submission rate at first service and conception rate at first service was also observed when analyzing data from Ferguson and Skidmore (2013). Some veterinarians and consultants in the field relate low conception rates to high submission rates. Contrary to this thinking, the lack of correlation between submission and conception rates observed in this study implies that conception rate is not necessarily sacrificed by inseminating at higher rates and not necessarily maximized by inseminating at lower rates. Moreover, Ferguson and Skidmore (2013) showed that conception rates at first service $>35 \%$ can be obtained, even with submission rates at first service $>74 \%$. These observations are important in a practical sense, given that dairy farms with poor submission rates but with relatively high conception rates might increase pregnancy rates simply by putting more effort on increasing estrus detection and submission rates. Alternatively, implementation of TAI programs may enhance reproductive performance by increasing the submission rate without necessarily decreasing the conception rate (Cartmill et al., 2001; Jordan, 2003).

Significant differences in submission rates were observed among reproductive cycles $(P<0.01$; Figure $2 \mathrm{~A})$. Submission rate was greatest when the breeding activities started (i.e., May). During this time, more cows in estrus are usually present within the herd. Therefore, the presence of a greater number of cows in estrus could have facilitated estrus detection and increased submission rates in this period (Roelofs et al., 2010; Walsh et al., 2011). In addition, restarting 


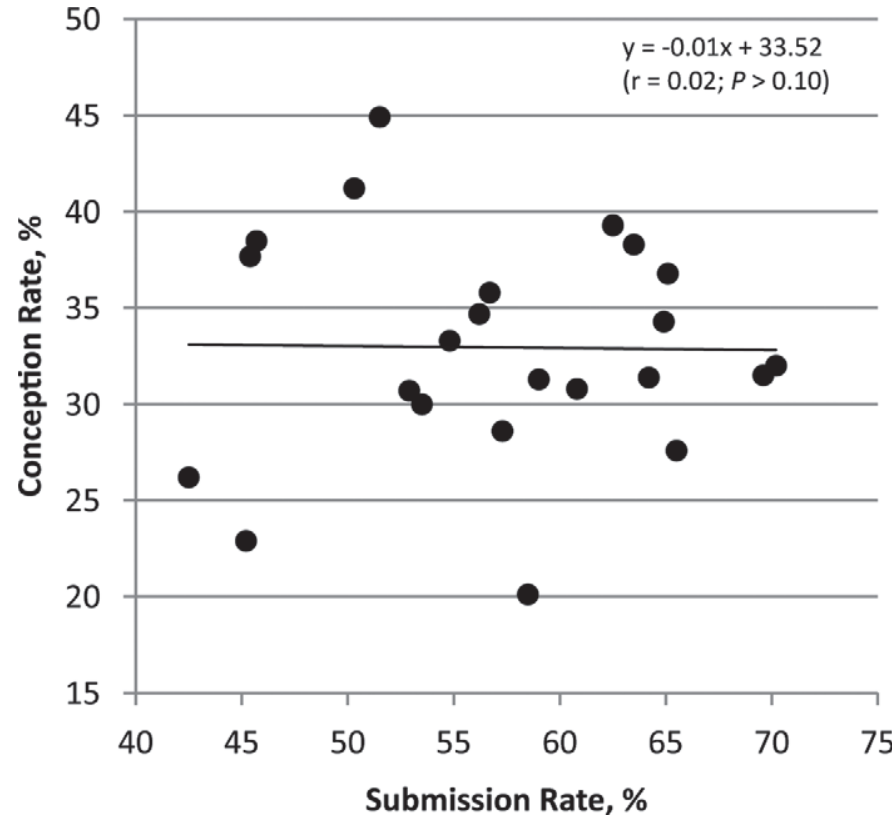

Figure 1. Relationship between conception and submission rates on 23 grazing-based dairy farms from western Buenos Aires province in Argentina. Data represent the estrus detection and conception rates accumulated in fourteen 21-d breeding cycles (dates on $\mathrm{x}$-axis indicate start date of each cycle). the breeding activities with an aggressive TAI program may explain the high submission rate in May (Cartmill et al., 2001; Jordan, 2003).

Significant differences in conception rates were also observed among cycles $(P<0.01$; Figure $2 \mathrm{~B})$. A first decrease of 5.1 percentage units in conception rate was observed during the spring (October-November). An additional decrease of 2.4 percentage units in conception rate was also observed during the summer (January-February). The spring decrease in conception rates could be related to excess $\mathrm{CP}$ in the diets, corresponding to high intakes of high-quality alfalfa, as typically observed in grazing systems of Argentina (Gallardo et al., 2005). Under grazing conditions, $\mathrm{CP}$ of the final ration can be high if alfalfa intake is relatively high (Gallardo et al., 2005). Decreased conception rates in Holstein heifers fed diets with high concentrations of protein were reported by Elrod and Butler (1993), who also observed the lowest conception rates in heifers with the highest concentrations of plasma urea nitrogen.

The summer decrease in conception rates would likely be attributed to heat stress (Cartmill et al., 2001; Jordan, 2003). Cartmill et al. (2001) reported that summer heat stress (i.e., temperature-humidity index $>72$ ) resulted in lower conception rates when cows were inseminated after a synchronized and detected estrus.

Table 2. Reproductive performance ${ }^{1}$ of 23 grazing-based dairy farms from the western region of Buenos Aires province in Argentina

\begin{tabular}{lcccc}
\hline Dairy & $\begin{array}{c}\text { No. of } \\
\text { cows }^{2}\end{array}$ & $\begin{array}{c}\text { Submission } \\
\text { rate, } \%\end{array}$ & $\begin{array}{c}\text { Conception } \\
\text { rate, } \%\end{array}$ & $\begin{array}{c}\text { Pregnancy } \\
\text { rate, \% }\end{array}$ \\
\hline A & 2,805 & 62.5 & 39.3 & 24.5 \\
B & 2,702 & 63.5 & 38.3 & 24.3 \\
C & 3,061 & 65.1 & 36.8 & 23.9 \\
D & 1,177 & 51.5 & 44.9 & 23.1 \\
E & 1,233 & 70.2 & 32.0 & 22.5 \\
F & 7,600 & 64.9 & 34.3 & 21.9 \\
G & 1,269 & 69.6 & 31.5 & 20.7 \\
H & 2,355 & 50.3 & 41.2 & 20.3 \\
I & 971 & 56.7 & 35.8 & 20.1 \\
J & 2,786 & 64.2 & 31.4 & 19.5 \\
K & 1,387 & 56.2 & 34.7 & 18.5 \\
L & 2,134 & 59.0 & 31.3 & 18.3 \\
M & 1,058 & 60.8 & 30.8 & 18.1 \\
N & 1,870 & 54.8 & 33.3 & 17.6 \\
O & 3,462 & 65.5 & 27.6 & 17.1 \\
P & 2,217 & 45.7 & 38.5 & 16.4 \\
Q & 1,272 & 45.4 & 37.7 & 16.2 \\
R & 6,664 & 57.3 & 28.6 & 16.0 \\
S & 1,521 & 52.9 & 30.7 & 11.7 \\
T & 2,994 & 53.5 & 30.0 & 11.1 \\
U & 1,842 & 58.5 & 20.1 & 10.3 \\
V & 1,960 & 42.5 & 26.2 & 18.8 \\
W & 3,600 & 45.2 & 22.9 & 4.04 \\
Average & - & 57.2 & 33.0 & 5.83 \\
SD & 7.97 & & & \\
\hline
\end{tabular}

${ }^{1}$ Data represent the submission and conception rates accumulated in fourteen 21-d breeding cycles.

${ }^{2}$ Number of cows eligible to get pregnant. 

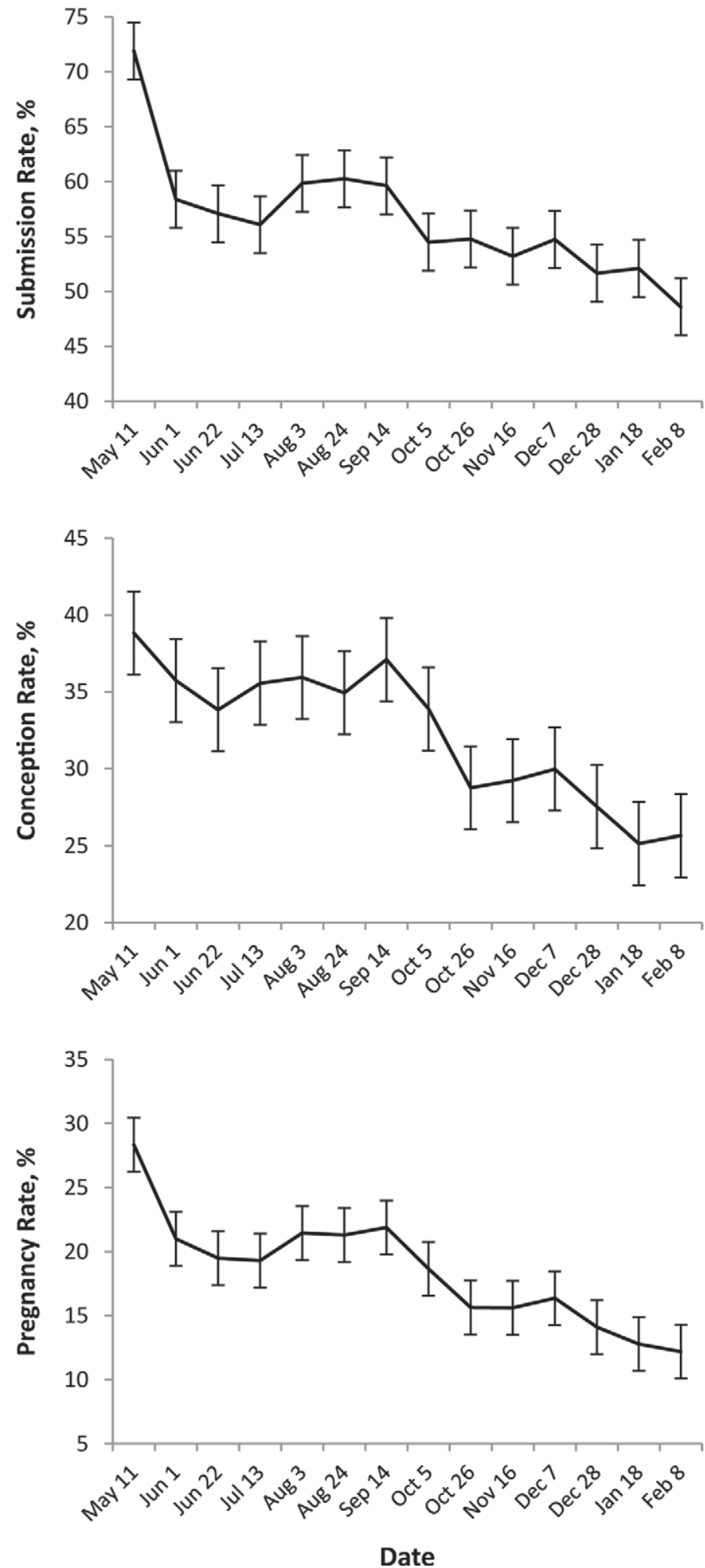

Figure 2. Seasonal variation of submission (A), conception (B), and pregnancy $(\mathrm{C})$ rates on 23 grazing-based dairy farms from western Buenos Aires province in Argentina. On average, initiation of breeding period started on May 11, 2011. Bars indicate standard error of the difference between cycles.
Roman-Ponce et al. (1977) reported conception rates of 44.4 and $25.3 \%$ for cows with and without shade, respectively. The latter conception rate is similar to those observed for the current data set during summer (Figure 2). Semi-extensive dairy systems, such as grazing systems in Argentina, are highly affected by temperature and humidity during the summer. Typically, in grazing systems in western BA, heat stress attenuation is limited to providing natural or artificial shade for a few hours between grazing periods, and sometimes, but not always, cooling cows with fans or sprinklers while they wait for milking (Table 1). Attenuating heat stress with shading or cooling for longer periods may be critical for maximizing conception rates in grazing systems from western BA.

\section{CONCLUSIONS}

No relationship was found between submission rate and conception rate in grazing dairy farms from western BA province. Dairy farmers could greatly improve pregnancy rates by increasing the number of cows inseminated (submission rate) through better estrus detection practices or implementation of TAI programs. Seasonal variation of submission and conception rates exists on grazing dairy farms in western BA. Efforts should focus on maintaining initial submission and conception rates to enhance reproductive performance, and likely profitability, of dairy farms in this region of Argentina.

\section{REFERENCES}

Cartmill, J. A., S. Z. El-Zarkouny, B. A. Hensley, T. G. Rozell, J. F. Smith, and J. S. Stevenson. 2001. An alternative AI breeding protocol for dairy cows exposed to elevated ambient temperatures before or after calving or both. J. Dairy Sci. 84:799-806.

de Vries, A., J. Van Leeuwen, and W. W. Thatcher. 2010. Economics of Improved Reproductive Performance in Dairy Cattle. Extension Document AN156. Institute of Food and Agricultural Sciences, University of Florida. Accessed Mar. 24, 2013. http://edis.ifas.ufl. edu/AN156.

Elrod, C. C., and W. R. Butler. 1993. Reduction of fertility and alteration of uterine $\mathrm{pH}$ in heifers fed excess ruminally degradable protein. J. Anim. Sci. 71:694-701.

Ferguson, J. D., and A. Skidmore. 2013. Reproductive performance in a select sample of dairy herds. J. Dairy Sci. 96:1269-1289.

Gallardo, M. R., A. R. Castillo, F. Bargo, A. A. Abdala, M. G. Maciel, H. Perez-Monti, H. C. Castro, and M. E. Castelli. 2005. Monensin for lactating dairy cows grazing mixed-alfalfa pasture and supplemented with partial mixed ration. J. Dairy Sci. 88:644-652.

Heersche, G., and R. L. Nebel. 1994. Measuring efficiency and accuracy of detection of estrus. J. Dairy Sci. 77:2754-2761.

Hutchinson, I. A., L. Shalloo, and S. T. Butler. 2013. Expanding the dairy herd in pasture-based systems: The role of sexed semen use in virgin heifers and lactating cows. J. Dairy Sci. 96:6742-6752.

Jordan, E. R. 2003. Effects of heat stress on reproduction. J. Dairy Sci. 86(E. Suppl.):E104-E114.

López, H., L. D. Satter, and M. C. Wiltbank. 2004. Relationship between level of milk production and estrous behaviour of lactating dairy cows. Anim. Reprod. Sci. 81:209-223. 
Roelofs, J., F. López-Gatius, R. H. Hunter, F. J. C. M. van Eerdenburg, and Ch. Hanzen. 2010. When is a cow in estrus? Clinical and practical aspects. Theriogenology 74:327-344.

Roman-Ponce, H., W. W. Thatcher, D. E. Buffington, C. J. Wilcox, and H. H. Van Horn. 1977. Physiological and production responses of dairy cattle to a shade structure in a subtropical environment. J. Dairy Sci. 60:424-430.

Walsh, S. W., E. J. Williams, and A. C. O. Evans. 2011. A review of the causes of poor fertility in high producing dairy cows. Anim. Reprod. Sci. 123:127-138. 